\title{
Surgical Management of Male Breast Cancer: A Tertiary Care Centre Experience
}

\author{
Authors \\ Vaibhav Vikas ${ }^{1}$, Naraindas Kewlani ${ }^{2}$ \\ ${ }^{1,2}$ Government Medical College, Thiruvananthapuram, Kerala, India
}

\begin{abstract}
Male breast cancer is an extremely rare condition with an incidence of 1/100000 men. The peak incidence is around the seventh decade of life. Risk factors for male breast cancer include genetic factors and hormonal abnormalities. Majority of the cases present in advanced stage due to lack of awareness. Pathologically, most of the cases are invasive ductal carcinoma. In this article we present a review of 3 cases of male breast cancer detected over a period of 4 years at a tertiary care health centre in India.
\end{abstract}

Keywords- Male breast cancer, ductal carcinoma, lobular carcinoma, modified radical mastectomy.

\section{Introduction}

Male breast cancer is a very rare entity accounting for about $1 \%$ of all malignant neoplasm in males ${ }^{[1]-}$ [4]. The estimated incidence is 1 case for each 100,000 men. Ninety percent of MBCs are invasive; of these, $80 \%$ are of no special type (so called ductal), $5 \%$ are papillary, and $1 \%$ are lobular ${ }^{[5]}$. Herein, we report a series of 3 cases of male breast cancer (invasive ductal carcinoma).

\section{Material and Methods}

All the males presenting with complains of breast swelling were evaluated. There were total of three cases of male breast cancer from August 2011 to July 2015. All the three cases were evaluated in detail including history, addiction, occupation, comorbidities and drug intake history. Modified Radical Mastectomy was done in all the three cases followed by primary closure in one and split skin thickness grafting of two cases. All the cases were followed for a period of 2 years and had no local or systemic complications.

First case, a 58 years old gentleman presented with complains of swelling over left chest since 2 years. On examination, an irregular painless mass of size about $10 \mathrm{cms} \times 12 \mathrm{cms}$ was present over the left mammary area with nipple in the centre of the mass. Mass was hard in consistency with peau'd orange appearance of the overlying skin. Mass was not fixed to the pectoralis major muscle but had restricted mobility. MRM was done. Primary closure of the skin flaps was not possible due to involvement of a large portion of skin in the mass. The defect was covered with a split skin thickness graft taken from the left thigh of the patient. Post operatively mild infection of graft was seen with approximately $95 \%$ uptake. No left upper limb lymphedema was observed during follow up. Histopathology report turned out to be invasive ductal carcinoma of breast. 
Second case, a 60 years old gentleman came with left breast swelling since two and a half years. On examination, a mass of size $6 \mathrm{cms} \times 8 \mathrm{cms}$ was present over left breast involving nipple areola complex. Modified Radical Mastectomy was done followed by split skin thickness graft of the exposed area. Graft was taken from right thigh. Post operative was uneventful with $100 \%$ graft uptake.

Third case, a 68 years old man presented with complains of swelling just under the right nipple since 1 year. On examination, a mass of approximately $1.5 \mathrm{cms}$ X $1.5 \mathrm{cms}$ was palpable just below the nipple. Trucut Biopsy of the lesion came out to be lobular carcinoma. Modified Radical Mastectomy was done with primary closure of the skin flaps. Histopathology report showed invasive ductal carcinoma.

\section{Results}

All the three cases were invasive ductal carcinoma pathologically. There was minor wound infection in first patient and was managed by regular cleaning and dressings. There had been no major complications in any of the three patients. All the three patients are doing well with no evidence of metastasis till date.

\section{Discussion}

Male breast cancer is most commonly seen in the age group of 60-70 years (unimodal distribution) as compared to the female breast cancer which has a bimodal age distribution (early-onset and late-onset peak incidences at 52 and 72 years old, respectively) [6]. There is a time gap of approximately 22 months from onset of symptoms to diagnosis in men (longer than in women); consequently men often present with advanced stage disease. Lack of awareness that men can also develop breast cancer also contributes to the late presentation.

Painless mass is the most common presentation seen in $13 \%$ to $90 \%$ of patients. One-third of patients present with changes in the nipple-areola complex (nipple fixation or retraction, inversion, oedema, or eczema). $75 \%$ cases may have bloody and $15 \%$ may have serous discharge. Ulceration of the skin is reported in about $27 \%$ of patients ${ }^{[7]}$. About $15 \%$ to $20 \%$ male breast cancer patients have a family history of breast cancer with mutation of BRCA gene playing an important role ${ }^{[8]}$. Major risk factors are Klinefelter's syndrome, cryptorchidism, orchitis, testicular trauma, orchiectomy, late puberty, infertility, old age, genetic, endocrine factors or exposure to ionizing radiation or female hormones. Hyperestrogenic conditions like obesity and cirrhosis may also cause male breast cancer. BMI more than $30 \mathrm{~kg} / \mathrm{m} 2$ in males pose a higher risk of breast cancer ${ }^{[9]}$.

Male and female breast carcinomas are biologically almost similar with some basic pathological differences. Male breast cancer are predominantly ductal in origin as the male breast normally contains ducts only and no lobules. Most common subtype of male breast cancer is infiltrating ductal carcinoma (84\% to 94\%). Ductal carcinomas in situ and lobular carcinoma $(1 \%)$ are rarer in males as compared with females. The early stage, ductal carcinoma in situ, is confined to ducts. Invasive ductal carcinoma invades the surrounding fatty tissues. Paget's disease of the nipple, lobular carcinoma and sarcoma are far less common in male breast compared to female. Lobular carcinoma is extremely rare due to absence of terminal lobules in the male breast ${ }^{[10],[11]} .90 \%$ of male breast cancer express ER (estrogen receptors), whereas 81-96\% express PR (progesterone receptors) ${ }^{[11]}$.

Diagnostic mammography in men has sensitivity and specificity of $92-100 \%$ and $90 \%$ respectively [12],[13]. It can correctly detect $80-90 \%$ of patients with breast cancer who present with suspicious masses. Mammographic features like well defined sub areolar lesions with calcifications in rare cases are suggestive of breast cancer. Small solid breast lesions can be diagnosed by ultrasound ${ }^{[13]}$. Fine needle aspiration with or without biopsy may be needed in high-risk patients to confirm the diagnosis. It can also provide an indication about potential response to hormonal treatment. In addition, it is neccesary to know the status of axillary lymph node to make preoperative staging and decision for neoadjuvant chemotherapy ${ }^{[12],[13]}$. Distant 
metastases may go to bone, lung, lymph node, liver and brain.

Modified Radical Mastectomy with or without reconstruction is most commonly used procedure. It involves removal of the ipsilateral breast tissue, the nipple-areolar complex, and axillary lymph nodes levels I and II (axillary lymph nodes underneath and lateral to the pectoral minor muscle) along with stripping of fascia of the pectoral major muscle ${ }^{[14]}$. Overall five year and ten year survival rate in various studies have been shown as $86 \%$ and $64 \%$ respectively. In node positive patients, the five and ten year survival rate decrease to $73 \%$ and $50 \%$ respectively. Due to advanced stage of neoplasm at the time of presentation, Modified Radical Mastectomy is the most often operation in male breast cancer ${ }^{[15]}$. Role of Breast-conserving therapy in male breast cancer is unclear ${ }^{[16]}$. Adjuvant hormonal therapy may have significance in male breast cancer patients because of estrogen and progesterone receptor positivity in most patients ${ }^{[17],[18]}$. Radiation therapy after surgery reduces risk of local recurrence of male breast cancer however the influence on survival is unknown.

\section{Conclusion}

Male breast cancer is a very rare disease. There should be efforts to increase awareness of male breast cancer among patients and physicians which will lead to presentation at an earlier stage. There is no prognostic difference between male and female breast carcinoma at similar stages. There should be high level of suspicion of male breast cancer in men with the above mentioned risk factors presenting with nipple discharge or breast swelling as detection and appropriate treatment at earlier stage can prevent advanced disease. Plastic surgeons can be of great help in conditions in which primary closure is not possible due to involvement of a large portion of skin in the tumor. In most of the cases split thickness graft is sufficient but flaps may be needed in cases of severe tissue loss.

\section{References}

1. Fentiman IS, Fourquet A, Hortobagyi GN: Male breast cancer. Lancet 2006, 367:595604.

2. Gennari R, Curigliano G, Jereczek-Fossa BA, Zurrida S, Renne G, Intra M, Galimberti V, Luini A, Orecchia R, Viale G, Goldhrisch A, Veronesi U: Male breast cancer: a special therapeutic problem. Anything new? (Review). Int J Oncol 2004, 24:663-670.

3. Weir HK, Thun MJ, Hankey BF, et al. Annual report to the nation on the status of cancer, 1975-2000, featuring the uses of surveillance data for cancer prevention and control. J Natl Cancer Inst. 2003; 95(17):1276-1299.

4. Jemal A, Siegel R, Ward E et al.: Cancer statistics, 2008. CA Cancer J Clin 2008; 58: 71-96.

5. Stalsberg H, Thomas DB, Rosenblatt KA, et al. Histologic types and hormone receptors in breast cancer in men: a population- based study in 282 United States men. Cancer Causes Control. 1993;4(2):143-151.

6. Anderson WF, Althuis MD, Brinton LA, Devesa SS: Is male breast cancer similar or different than female breast cancer? Breast Cancer Res Treat 2004, 83:77-86.

7. Agrawal, A., Ayantunde, A. A., Rampaul, R. \& Robertson, J. F. Male breast cancer: a review of clinical management. Breast Cancer Res Treat, 2007;103(1), 11-21.

8. Korde LA, Zujewski JA, Kamin L et al.: Multidisciplinary meeting on Male Brest cancer: summary and research recommenddations. J Clin Oncol 2010; 28(12): 21142122.

9. Brinon LA, Richesson DA, Gierach GL et al.: Prospective evaluation of risk factors for male breast cancer. J Natl Cancer Inst 2008; 100(20): 1447-1481.

10. Goodman, M. T., Tung, K. H., Wilkens, L. R. Comparative epidemiology of breast cancer among men and women in the US, 
1996 to 2000. Cancer Causes Control, 2006;17(2):127-36.

11. Lanitis, S., Rice, A. J., Vaughan, A., Cathcart, P., Filippakis, G., Al Mufti, R., Hadjiminas, D. J. Diagnosis and management of male breast cancer. World J Surg, 2008;32(11):2471-6.

12. National Cancer Institute. Surveillance Epidemiology and End Results (SEER): Cancer Statistics. Bethesda (MD): National Cancer Institute 2011. http://seer.cancer.gov/statistics/

13. Gomez-Raposo C, Zambrana Tevar F, Sereno Moyano $\mathrm{M}$ et al.: Male breast cancer. Cancer treat rev 2010; 6(6): 451- 457.

14. De los Santos, J. F. \& Buchholz, T. A. Carcinoma of the male breast. Curr Treat Options Oncol, 2000;1(3):221-7.

15. Kiluk JV, Lee MC, Park CK et al.: Male breast cancer: management and follow-up recommendations. Breast J 2011; 17(5): 503-509.

16. Cutuli B, Le-Nir CC, Serin D et al.: Male breast cancer: evolution of treatment and prognostic factors: analysis of 489 cases. Crit rev Oncol Hematol 2010; 73(3): 246254.

17. Ribeiro G, Swindell R: Adjuvant tamoxifen for male breast cancer (MBC). Br J Cancer 1992; 65(2): 252-254.

18. Ribeiro GG, Swindell R, Harris $M$ et al.: A review of the management of the male breast carcinoma based on an analysis of 420 treated cases. Breast 1996; 5: 141-146. 